\title{
El derecho humano a la propiedad de los pueblos originarios y su reconocimiento constitucional
}

\author{
Alejandra Olivares Muñoz (iD \\ Universidad de Chile
}

\begin{abstract}
g Miranda Torres, Roxana Paola. Los pueblos originarios en Latinoamérica y el derecho humano a la propiedad. Ciudad de México: Tirant lo Blanch, 2019, 204 páginas.
\end{abstract}

Roxana Miranda Torres es doctora en Derecho por la Universidad Panamericana, México, campus Guadalajara, además de profesora e investigadora de esa misma casa de estudios. Con años de trayectoria en el área, su línea de investigación se centra en la situación de los pueblos originarios de México, estudiando en específico las materias de pluralismo jurídico, nomología ${ }^{1}$ y justicia electoral ligada a estas comunidades. Sin embargo, en la obra objeto de esta recensión, la autora extiende su examen a otras realidades latinoamericanas, al analizar en conjunto los ordenamientos jurídicos de Bolivia, Colombia, Ecuador y Perú, países que se han pronunciado sobre los derechos de estos pueblos.

El objeto de estudio del libro dice relación con el despojo de las tierras que ancestral e inmemorialmente han pertenecido a los pueblos originarios de América Latina, los cuales durante siglos se han visto oprimidos por una concepción mestiza dominante, que se ha encargado de desconfigurar no sólo su identidad, sino también su derecho humano a la propiedad, con la finalidad de extraer de forma inconsciente los recursos naturales presentes en ellas, en un afán depredador propio del neoliberalismo y de la globalización imperantes en estos tiempos. Esto pone en serio peligro la continuidad de la cultura ancestral de estas comunidades, dejándolas al borde del etnocidio.

1. «La nomología es una transdisciplina que tiene por objeto el estudio de las normas de una agrupación humana en una circunstancia específica, lo cual implica tiempos y espacios determinados y una dialéctica propia, específica y característica de su evolución que causa y produce conceptos, categorías, ideales, valores, principios y creaciones culturales particulares que se deben entender en la circunstancia en que se crean los procesos sociales normativos». Covarrubias Dueñas (2016), Constitución para México 2017. Necesidad de una norma rectora. México: Editorial Porrúa, citado por Miranda Torres (p. 30). 
A partir de un análisis interdisciplinario con elementos de derecho, historia, estadísticas y análisis de casos, la autora construye con habilidad el panorama de la región, lo que permite al lector comprender en forma íntegra el problema de la propiedad de las tierras indígenas y sus implicancias a corto y largo plazo, en que su expropiación constituye, a juicio de la doctora Miranda Torres, la «amenaza principal» a los pueblos originarios latinoamericanos.

En cuanto a su estructura, el libro se encuentra dividido en cuatro capítulos. El primero aporta datos demográficos que dan cuenta del multiculturalismo que permea a América Latina, para luego sumergir al lector en la comprensión de conceptos sumamente relevantes en la materia. En primera instancia, traza los límites entre las categorías de «indio», «pueblos indígenas» y «pueblos originarios», criticando la función sicológica y peyorativa de la primera, mientras reivindica, en cambio, el uso de la última y del término «comunidades autóctonas», pues deriva de la idea de comunidad, es decir, de lo que pertenece a todos y no es exclusivo de alguien (p. 23).

Luego, la autora acerca al lector al entendimiento de la realidad de estos pueblos, a través de los conceptos de cosmovisión y cosmogonía, los cuales dotan de un contenido «mágico religioso» a la relación de los pueblos originarios con sus tierras, en que «el hombre y el mundo son uno solo, pareja firme que se liga con un lazo estrecho e indisoluble». Después, desde un análisis histórico-jurídico, la doctora Miranda Torres analiza las etapas del constante proceso de despojamiento de las propiedades indígenas, problemática común en la realidad latinoamericana y que se remonta a la época de la Conquista, para pasar luego a los estadios de independencia y posterior globalización, hasta definitivamente arribar al neoliberalismo, hoy imperante en el continente, en el cual lo común en estas etapas se encuentra constituido por la opresión de la clase dominante a la concepción del mundo de los pueblos indígenas, en desmedro de sus derechos $a b$ origene de propiedad sobre sus tierras. Tras definir la problemática que afecta a los pueblos originarios, la autora identifica un importante giro, pues estos pueblos pasan de ser sujetos históricamente anulados a ser contemplados en los textos constitucionales de varios países latinoamericanos, junto con la consagración del respeto por el medio ambiente.

En el segundo capítulo, la autora emprende una revisión de los aspectos generales de cada país estudiado (extensión territorial, población y, ciertamente, los pueblos originarios que allí habitan), para luego pasar al análisis de casos de explotación, invasión y depredación de las tierras de estos pueblos, blanco de extracción extranjera debido a la gran riqueza en recursos naturales. El cierre de este capítulo está constituido por el examen del marco constitucional y legal que regula el reconocimiento de los pueblos originarios de cada uno de los Estados. Al respecto, destaca el contenido de las constituciones de Bolivia y Ecuador, las que a través de la incorporación del Suma Qamaña (buen convivir aymara boliviano) y Sumak Kawsay (buen vivir quechua ecuatoriano), logran conciliar el mundo de lo mestizo con el mundo indígena, 
introduciendo elementos propios de la cosmovisión y cosmogonía de los pueblos originarios, que promueven un estilo de vida en que el respeto por la naturaleza constituye la piedra angular de una vida en comunidad.

Ya en el tercer capítulo, la doctora Miranda Torres redirecciona su investigación al derecho internacional. No sólo analiza la regulación que los instrumentos internacionales han otorgado a los derechos de estos grupos, sino que además examina resoluciones de la Comisión Interamericana de Derechos Humanos e importantes casos contenciosos ventilados ante la Corte Interamericana de Derechos Humanos, en relación con el derecho a la propiedad sobre sus tierras. Así, expone el panorama general de los estándares internacionales de derechos humanos en la materia, los cuales no son sino fruto de las arduas luchas lideradas por los propios pueblos originarios en búsqueda de su reconocimiento y la protección de sus derechos ancestrales.

En el capítulo cuarto, la autora profundiza en una serie de lineamientos jurídicos mínimos e indispensables para la efectiva protección del derecho humano a la propiedad de los pueblos originarios. Esto dota a la obra de una virtuosa completitud de contenido, al revisar los conceptos de autonomía y libre determinación, derecho a la consulta y el consentimiento previo, libre e informado, desarrollo sostenible, necesidad de un orden planetario, entre otros, lo que permite al lector crear una base de sólidos cimientos respecto de materias concernientes a los pueblos originarios y su debida protección.

El cierre de esta obra, a ojos de quien redacta esta recensión, no es sino el fiel relato del profundo compromiso de protección de los derechos humanos de los pueblos originarios que ha conservado la autora durante los años de investigación en el tema. Plantea aquí una serie de propuestas que se extienden a la realidad de cada país latinoamericano, invitándonos, entre otras cosas, a «considerar a los pueblos originarios como una parte fundamental de nuestra identidad latina», lo que nos recuerda que nuestra raíz se encuentra precisamente en ellos.

El libro de la doctora Miranda Torres, a su vez, se configura como un imperativo de lectura de cara al proceso constituyente, puesto que presenta una revisión constitucional y legal de cinco países pertenecientes al nuevo constitucionalismo latinoamericano sobre materias concernientes a los pueblos originarios, en el que da a conocer sus puntos fuertes y aquéllos que precisan de mejoras, experiencias que, con toda seguridad, son dignas de ser estudiadas para nutrir nuestro debate constitucional interno.

Cambiar nuestra historia constitucional, marcada por una única referencia a los pueblos originarios, la que tiene, además, un tinte peyorativo, ${ }^{2}$ es uno de los grandes

2. Nos referimos al artículo 47 de la Constitución Política del Estado de Chile de 1822, el cual señala: «Corresponde al Congreso: 6. Cuidar de la civilización de los indios del territorio». 
desafíos del Chile actual. Es menester hacerlo desde una mirada de derechos humanos, siguiendo el camino trazado décadas atrás por numerosos países de la región.

Así las cosas, la obra es una invitación a actuar en favor de la protección de los derechos humanos de los pueblos originarios y, en especial, de su derecho ancestral de propiedad sobre sus tierras, corazón de la cultura de estas comunidades y pieza clave en la continuidad de su existencia. Estos derechos deben ser efectivamente consagrados y protegidos a nivel constitucional, además de robustecidos en la normativa legal, objetivo al que sólo arribaremos a través del irrestricto respeto a su nomología, cosmovisión y cosmogonía.

\section{Sobre la autora}

Alejandra Olivares Muñoz es egresada de Derecho de la Universidad de Chile. Fue ayudante de las cátedras de Derecho Constitucional y de Orden Público y Recursos de Protección y Amparo Económico. Cursó un intercambio académico en la Universidad de São Paulo, Brasil. Actualmente es ayudante ad honorem del Centro de Derechos Humanos de la misma casa de estudios. Su correo electrónico es alejandra.olivaresmunoz@gmail.com. (D) https://orcid.org/o0oo-0001-8326-130X. 
El Anuario de Derechos Humanos es una publicación semestral de referencia y consulta en materia de derechos humanos y campos afines. Busca ser un espacio de discusión de los temas centrales en el ámbito nacional e internacional sobre derechos humanos. Es publicado desde 2005 por el Centro de Derechos Humanos de la Facultad de Derecho de la Universidad de Chile.

\author{
EDITORA \\ Claudia Iriarte Rivas \\ ciriarter@derecho.uchile.cl \\ SITIO WEB \\ anuariocdh.uchile.cl \\ CORREO ELECTRÓNICO \\ anuario-cdh@derecho.uchile.cl \\ LICENCIA DE ESTE ARTÍCULO \\ Creative Commons Atribución Compartir Igual 4.o Internacional
}

\author{
\% \\ La edición de textos, el diseño editorial \\ y la conversión a formatos electrónicos de este artículo \\ estuvieron a cargo de Tipográfica \\ (www.tipografica.io)
}

